Франгулян Л. Р.

Аннотация. Цель исследования - проанализировать сюжеты в коптской агиографии, в которых засвидетельствован образ облака. Средневековые авторы текстов в честь святых часто апеллируют к библейским сюжетам и мотивам, поэтому в статье рассматриваются библейское использование образа облака и его трансформация в коптской агиографии. Научная новизна исследования состоит в сравнительном анализе изучаемого образа в коптской агиографии и в Библии, который не проводился до настоящего момента. В результате доказано, что образ облака, с одной стороны, основан на библейском тексте, с другой, имеет свои самобытные черты в коптской агиографии, как, например, исцеление тела святого.

\title{
EN Image of Cloud in Coptic Hagiography: Origins and Functions
}

\author{
Frangulian L. R.
}

\begin{abstract}
The aim of the study is to analyse the plots in Coptic hagiography, in which the image of a cloud is attested. Medieval authors of texts written in honour of the saints often appeal to biblical plots and motives. Therefore, the article examines the biblical use of the image of a cloud and its transformation in Coptic hagiography. The scientific originality of the research lies in the comparative analysis of the studied image in Coptic hagiography and in the Bible, which has not been carried out until now. As a result, it was proved that the image of a cloud, on the one hand, is based on the biblical text, and on the other hand, it has its own distinctive features in Coptic hagiography, such as the healing of a saint's body.
\end{abstract}

\section{Введение}

Актуальность настоящего исследования определяется тем, что анализируемый образ в коптской агиографии не получил должного изучения. Этот пласт литературы привлекает мало внимания исследователей вследствие невысокого уровня художественности и шаблонности многих текстов. Однако если не применять к агиографическим текстам современные требования, а изучать их как литературу, которую ее читатели слушали/читали с интересом, то можно определить, как агиографы использовали сюжеты, мотивы и образы, известные им по другим текстам.

Указанная цель может быть достигнута в ходе решения следующих задач: во-первых, для исследования образа облака необходимо отобрать среди многочисленных агиографических текстов на коптском языке те, которые содержат этот образ, и в таком количестве, которое будет репрезентативно, позволяя остаться в рамках статьи; во-вторых, проанализировать образ облака на библейском материале; в-третьих, сравнить функции, выполняемые изучаемым образом в тексте Библии и в коптской агиографии.

Для успешного решения поставленных задач используется сравнительно-сопоставительный метод исследования. Он позволяет проанализировать, с одной стороны, истоки образа облака, с другой, какие функции возложили на него в своих текстах коптские агиографы.

Теоретической базой исследования послужили работы в области каталогизации библейских образов (Лонгман, Райкен, Уилхойт, 2005), использования библейских образов в христианских текстах (Балаховская, 2020; Балаховская, 2016; Воробьева, Селезнева, 2020; Duncan, 2000), систематизации коптской агиографии (Delehaye, 1921; Papaconstantinou, 2011) и др.

Практическая значимость проводимого исследования состоит в том, что его выводы могут быть использованы в ходе подготовки учебных пособий и монографий по истории коптской литературы, шире - по средневековой агиографии, по изучению литератур Востока, а также при написании спецкурсов по агиографии и библеистике. 


\section{Основная часть}

Коптская агиография представляет собой огромный пласт литературы в честь святых. Как утверждает А. Папаконстантину, простые копты интересовались в первую очередь именно агиографическими текстами и, возможно, знали их содержание лучше, чем Библию (Раpaconstantinou, 2002, с. 521). Как и любая средневековая литература, коптская агиография была написана с ориентиром на образец в сюжетах, мотивах, образах (Аверинцев, Андреев, Гаспаров и др., 1994, с. 15). Однако при этом у агиографов оставалась свобода при выборе используемых сюжетов, их сочетании и даже преобразовании.

Главными источниками образцов для египтян-христиан были, во-первых, библейский нарратив, во-вторых, византийская агиография. Однако иногда даже самое простое использование прототипов при глубоком анализе показывает, что в аутентичной среде они самобытны и имеют дополнительные коннотации. Например, в книге Деяний описано явление Христа первомученику Стефану перед побиванием его камнями (Деян. 7.56). В коптских мученичествах этот сюжет представлен следующим образом: Христос является мученику перед казнью и обещает ему, что любой, кто почтит мученика, перепишет текст его мученичества и т.д., получит блага от Бога (Martyre de saint Macaire, 1886, с. 66-67; Apa Chamoul, 1910, с. 183-184; Martyrologe de saint Piroou..., 1886, с. 169-170). Иногда это не монолог, а диалог, в котором мученик просит явившегося Христа за тех, кто будет ему молиться, построит храм в его честь и т.д., чтобы Бог им во всем помог (Nouveau martyr copte..., 1918, с. 256-257). Так, новозаветный сюжет стал пространнее и дополнен заключением соглашения между Богом и мучеником, которое, в свою очередь, тоже восходит к библейскому нарративу (например, Быт. 17.1-16; Исх. 19.3-6).

Образ облака в коптской агиографии встречается довольно часто. Перечислим выбранные нами сюжеты. Во-первых, они обнаружены в ряде мученичеств, последние редакции которых датируются VII-VIII вв., а сами тексты описывают события III-IV вв., период гонений от язычников:

1. «Мученичество Иоанна и Симеона». Текст сохранился полностью и отличается от других мученичеств тем, что посвящен по большей части биографии египтянина-подвижника Иоанна и его чудесной помощи людям. Симеон, двоюродный брат Иоанна, был его учеником, свидетелем чудес и был казнен языческим правителем вместе с Иоанном за исповедание христианства. Сюжет с облаком таков. В Антиохии у императора заболевает дочь. Он услышал об исцелениях, совершенных Иоанном, и отправил за ним посланников. Иоанн же чудесным образом узнал об этом и попросил Бога перенести его из Египта в Антиохию так, чтобы он был избавлен от опасного водного пути. Затем «облако света подняло его и отнесло в город Антиохию, опустило во дворце на кровать, где спал император» (перевод автора статьи. - Л. Ф.). После исцеления императорской дочери облако точно так же перенесло Иоанна обратно домой, хотя правитель схватил его за пояс и не хотел отпускать (Martyrologe de saint Jean..., 1886, с. 188-189, 191).

2. «Мученичество Пироу и Атома». Текст сохранился полностью. Во время пытки раскаленными гвоздями на огненном железном ложе сначала раздался гром и появились молнии, затем дождевое облако начало проливать дождь над святыми и погасило пламя, которое стало для святых как роса. Их тела также были полностью исцелены. После этого гонитель заключил их в тюрьму (Martyrologe de saint Piroou, 1886, с. 144).

3. «Мученичество Чамула». Текст сохранился не полностью, отсутствует начало. Когда гонитель-язычник хочет убить Чамула мечом, облако света распространилось над мучеником. Это остановило гонителя и внушило ему, что он не может ничего сделать с мучеником, поэтому он перестал пытать святого и заключил в тюрьму (Apa Chamoul, 1910, с. 176-177).

4. «Мученичество Апатила». Текст сохранился полностью. Во время пытки в огне, куда был помещен уже раненый святой, Бог послал облако, которое окружило Апатила, и дождь из него потушил огонь, а тело святого было исцелено от всех повреждений. Гонитель заключил святого в тюрьму и потом, не продолжая пытки, отправил к другому гонителю (†мартүріа ктє піагіос..., 1907, с. 94).

5. «Мученичество Епимы». Текст сохранился полностью. Связанного железными путами святого пытали на раскаленном железном ложе. Появившееся облако света и росы распространилось над ложем, и роса погасила пламя, а тело святого полностью исцелилось от ран. Затем неожиданно гонитель вместе с воинами ослеп. После исцеления мучеником он отправил Епиму к другим гонителям, потому что местные жители, свидетели чуда, были против пыток святого (Le Martyre d’Apa Epima, 1937, с. 28).

Также образ облака был обнаружен в ряде житий:

1. «Житие Иоанна Колова (Малого)», написанное Захарией, епископом г. Саха в конце VII в. В этом тексте описывается, как Феофил Александрийский (385-412) построил мартирий для мощей трех отроков, Анания, Азария и Мисаила, известных по ветхозаветному рассказу, и молил Бога получить эти мощи. Феофилу было открыто, что это может сделать Иоанн Колов, и он вызвал его из Скита в Александрию и попросил об этом, пожелав безопасной дороги. Когда Иоанн вышел из города, облако перенесло его в Вавилон, в место, где были захоронены мощи. Там он получил ответ святых, и потом облако доставило его обратно в окрестности Александрии (Zacharie, 1894, с. 384, 387).

2. «Житие Шенуте», написанное Бесой, его учеником, во второй половине V в. Шенуте (348-466) - известный коптский монах и церковный деятель, настоятель Белого монастыря. Образ облака в житии засвидетельствован несколько раз. Во-первых, в связи с ересью Нестория Шенуте был вызван в Эфес на III Вселенский Собор (в официальных актах Собора он не указан, возможно, это псевдоисторический сюжет). По пути 
обратно служители патриарха не узнали Шенуте, и ему было запрещено возвращаться с патриархом на корабле. Когда Шенуте обратился ко Христу с молитвой, то облако света «сошло с неба и подняло его (вместе) с учеником... Когда же они достигли моря, взглянул вверх авва Кирилл архиепископ, и увидел моего отца апу Шенуте в середине облака вместе со своим учеником, и воскликнул, говоря: “Благослови нас, наш отец святой, новый Илия!”. Сказал мой отец апа Шенуте ему: “Помяни меня, о мой отец святой”. И таким образом облако летело с ним и принесло его в его монастырь» (Житие Шенуте..., 2001, с. 124; Sinuthii archimandritae vita, 1906, с. 16). Отдельно дальше отмечается, что в тот же день, когда патриарх еще плыл, Шенуте уже был в монастыре (Sinuthii archimandritae vita, 1906, с. 17). Во-вторых, агиограф пишет, что однажды Шенуте был перемещен с помощью облака света (Sinuthii archimandritae vita, 1906, с. 31) из монастыря в Константинополь в покои царя, который послал за ним гонца, чтобы получить благословение, а затем таким же образом возвращен обратно. В-третьих, Шенуте помог местному правителю победить варваров, явившись посередине битвы в облаке света с огненным мечом в руках. Правитель тоже был вознесен этим облаком и бился так с врагами (Sinuthii archimandritae vita, 1906, с. 52).

3. «Житие Лонгина и Луция», написанное, предположительно, во второй половине V в. и повествующее о двух монахах. Однажды к подвижникам пришло много людей, а хлеб для раздачи им лежал на солнце. Неожиданно пошел дождь. Лонгин помолился, и облака прошли мимо того места, где находился хлеб, и ни капля воды не попала на него (Vite dei monaci..., 1975, с. 72).

4. «Житие Писентия», дошедшее в рукописи XI в. и написанное, предположительно, в VIII-IX вв. Писентий был известным епископом г. Кефт, жившим в VI-VII вв. В этом житии пересказывается ветхозаветный сюжет с видением Иаковом лестницы, по которой сходят и восходят ангелы, и Господь стоит на ней и обещает Иакову многочисленное потомство и благословение (Быт. 28.12-16). Однако в житии лестница заменена на облако (The Life of Bishop Pisentius..., 1913, с. 83), хотя в коптской Библии в этом сюжете упоминается, как и во всех традициях, лестница.

Образ облака достаточно часто встречается в Библии. Приведем значимые упоминания. Из них реже засвидетельствованы те, которые связаны с описанием погодных условий (например, 3 Цар. 18.44). Во многих сюжетах облако ассоциируется с Богом. В Книге пророка Иоиля судный день Господень обозначен как «день тьмы и мрака, день облачный и туманный» (Иоиль 2.2). Частный суд также описан с появлением облака: «И в Тафнисе померкнет день, когда Я сокрушу там ярмо Египта, и прекратится в нем гордое могущество его. Облако закроет его, и дочери его пойдут в плен» (Иез. 30.18).

Облака сопровождают Господа при появлении Его на земле. В книге Исход хорошо известен сюжет с облачным столпом, в котором шел сам Господь и который освещал путь еврейскому народу в пустыне (Исх. 13.21-22; 14.19-20, 24). Облако обозначало присутствие Бога в Скинии (Исх. 33.9-10; 40.34-38; Лев. 16.2; Чис. 9.15-23), позже - в храме (3 Цар. 8.10-11; 2 Пар. 5.13-14). Пророк Исайя в пророчестве о Египте говорит: «Вот, Господь восседит на облаке легком и грядет в Египет» (Ис. 19.1). Облака находятся во власти Бога: «Он заключает воды в облаках Своих, и облако не расседается под ними» (Иов 26.8); «Господь творит все, что хочет, на небесах и на земле, на морях и во всех безднах; возводит облака от края земли, творит молнии при дожде, изводит ветер из хранилищ Своих» (Пс. 134.6-7). В то же самое время образ облака используется, чтобы показать величие Бога: «...в вихре и в буре шествие Господа, облако - пыль от ног Его» (Наум. 1.3). Наконец, широко известен мотив радуги как обещания Бога, что не будет больше потопа. Однако стоит отметить, что Господь каждый раз говорит о радуге в облаке (Быт. 9.13, 14, 16).

В Новом Завете облако упоминается в сюжетах со Христом: Бог-Отец прославил Его из облака во время преображения (Мф. 17.5; Мк. 9.7; Лк. 9.34); облако скрыло из вида Христа при вознесении (Деян. 1.9); оно будет сопровождать Его появление при конце света (Мф. 24.30; Мк. 13.26; Лк. 21.27; Откр. 1.7). Люди же, оставшиеся в живых при Апокалипсисе, будут возведены на небо на облаках (1 Фес. 4.17).

Рассматриваемый образ используется авторами Библии и вне связи с Богом. Иов приводит облако в качестве примера непостоянства: «Редеет облако и уходит; так нисшедший в преисподнюю не выйдет» (Иов 7.9; Oc. 6.4, 13.3). В Послании к евреям образ облака использован метафорически в положительном ключе: «Посему и мы, имея вокруг себя такое облако свидетелей, свергнем с себя всякое бремя» (Евр. 12.1). Однако засвидетельствована и отрицательная коннотация образа, в случае, когда облако не дает долгожданного дождя. Например, оно приравнивается к человеку, хвастающемуся ложными подарками (Притч. 25.14), к распутным людям на вечери любви (Иуд. 1.12).

В приведенных нами коптских текстах слово «облако» не используется в метафорическом ключе или в качестве сравнения. Однако оно всегда соотносится с проявлением чудес, что отражено в словосочетании «облако света». Положительность образа облака говорит о его знаковости: оно знаменует собой, что Бог присутствует здесь и помогает. Лишь в одном случае можно говорить об этом образе, что он рисует погодные условия, но и здесь облако подчинилось молитве Лонгина, и дождь не намочил хлеба.

В двух сюжетах упоминаются ветхозаветные реалии, и в каждом из них можно отметить своеобразие. В «Житии Шенуте» летящего на облаке монаха сравнивают с Илией, хотя тот не перемещался на облаке, а был взят на небо на огненной колеснице (4 Цар. 2:11). Возможно, автор имел в виду вообще всякое воздушное перемещение и потому использовал такое сравнение. Ветхозаветный сюжет, описанный в «Житии Писентия», содержит указанную выше ошибку. Ее истоки, скорее всего, кроятся в фонетической схожести

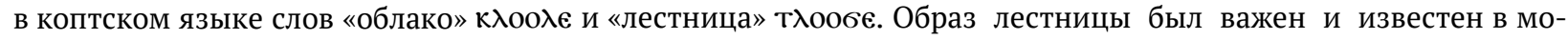
нашестве, а сами библейские сюжеты редко менялись авторами по собственной воле. Поэтому здесь опечатка переписчика, а не измышление агиографа. 
В Ветхом Завете никто из людей не перемещался на облаке, Новый Завет уже открыл такую возможность. В коптских текстах перенесение святого из одного места в другое на облаке можно считать житийным сюжетом. Его использование в «Мученичестве Иоанна и Симеона» оправдано, потому что первая часть этого памятника, в которой упоминается рассматриваемый сюжет, относится к жанру «житие». Можно отметить акцент, сделанный авторами на быстром передвижении между пунктами и на избавлении от опасности в результате такого способа перемещения. Кроме того, святого на облаке невозможно задержать человеческими усилиями. В первом упоминаемом эпизоде в «Житии Шенуте» дополнительной коннотацией становится возвеличивание святого после унижения. Важным элементом можно назвать молитву святого к Богу с просьбой о помощи попасть куда-либо, т.е. Бог управляет облаком, а не святой. В библейском же нарративе передвижение Бога на облаке не ассоциируется с необходимостью, а лишь оттеняет Его величие.

В одном сюжете подвижник не просто был перенесен на облаке, но пребывал на нем (Шенуте), и даже другой человек, не святой, присоединился к нему. Настоятель монастыря имел в руке огненный меч, облако использовалось в битве - дополнительной коннотацией становится победоносность. А сочетание огня и облака также встречается в Библии в отношении Бога (например, столп перед иудеями днем был из облака, ночью - из огня), что снова намекает на божественное присутствие при описываемых событиях.

Наконец, в коптских мученичествах основная функция облака - спасение от пытки и ее последствий. В этом можно увидеть библейскую коннотацию судейства, представленную наоборот: используя облако, в одном случае Бог судит, в другом - прекращает суд. Кроме того, после чудесного спасения пытки или останавливаются вообще, или временно, и гонитель отправляет святого к другому представителю власти, т.е. меняется ход повествования, и благодаря этому используемый образ получает особую значимость в текстах. Немаловажным мотивом становится физическое исцеление после соприкосновения с облаком или дождем из него. Такая функция облака отсутствует в библейских текстах, но она отражает коптское самобытное представление о необходимости сохранить целостность тела. Т. Баумайстер считает такую концепцию древнеегипетским рудиментом и отмечает его наличие во многих коптских мученичества (Baumeister, 1972, с. 169-170).

\section{Заключение}

Данное исследование позволяет сделать предварительные выводы, основанные на изучении девяти агиографических текстов на коптском языке. Библейские образы, несомненно, легли в основу образа облака, используемого в памятниках, и оказали влияние на выполняемые им следующие функции: 1) передвижение на облаке, которое отличает быстрота, сохранность от опасностей, непредотвратимость; 2) ознаменование присутствия Бога благодаря чудесным элементам; 3) подчинение Богу. Функция божественного суда претерпела изменение в противоположное значение: с облаком связана не кара Господня, а прекращение Богом наказания, предписанного гонителем святому. При этом в коптских житиях облако и огонь соседствуют, а в мученичествах противопоставляются, так как второй элемент гасит первый. Поэтому однозначности одного природного элемента (облако) противопоставляется бинарность другого (огонь). Невозможно не отметить трансформацию, которую претерпел образ облака в коптской традиции, и его дополнительные коннотации победоносности, возвеличивания после унижения, исцеления от ран. В одном случае отмечается опечатка переписчика.

Перспективы дальнейшего изучения поднятой темы заключаются в расширении круга коптских источников, в том числе с прибавлением греческой и латинской агиографии, также открывается возможность сравнить образы облака и огня, увеличить набор анализируемых библейских образов, связанных с погодными явлениями и используемых в коптской агиографии, и составить их каталог.

\section{Источники | References}

1. Аверинцев С. С., Андреев М. Л., Гаспаров М. Л., Гринцер П. А., Михайлов А. В. Категории поэтики в смене литературных эпох // Историческая поэтика: литературные эпохи и типы художественного сознания: сб. статей. М.: Наследие, 1994.

2. Балаховская А. С. Агиографический нарратив и его интерпретации (на материале агиографии Иоанна Златоуста) // Studia Litterarum. 2020. № 5/2.

3. Балаховская А. С. Образ Иоанна Златоуста в контексте образа пророка Илии в византийской агиографии // Индоевропейское языкознание и классическая филология - XX (1). Материалы чтений, посвященных памяти профессора Иосифа Моисеевича Тронского. СПб.: Наука, 2016.

4. Воробьева С. Н., Селезнева Л. В. Библейские образы как константы религиозного дискурса (на примере апокрифической литературы) // Дискурс-Пи. 2020. № 1 (38).

5. Житие Шенуте, составленное Бесой // Изречения египетских отцов / введ., пер., комм. А. Еланская. СПб.: Алетейя, 2001.

6. Лонгман Т., Райкен Л., Уилхойт Д. Словарь библейских образов. СПб.: Библия для всех, 2005.

7. Apa Chamoul // Coptic Texts on Saint Theodore the General / ed., transl. E. O. Winstedt. L. - Oxford, 1910.

8. Baumeister Th. Martyr Invictus: der Martyrer als Sinnbild der Erlösung in der Legende und im Kult der fruhen koptischen Kirche. Münster: Verlag Regensberg, 1972.

9. Delehaye H. Les passions des martyrs et les genres littéraires. Bruxelles: Bureaux de la Sociétédes Bollandistes, 1921. 
10. Duncan S. Signa De Caelo in the Lives of St Cuthbert: The Impact of Biblical Images and Exegesis on Early Medieval Hagiography // Heythrop Journal. 2000. Vol. 41. Issue 4.

11. Le Martyre d’Apa Epima / éd., transl. T. Mina. Caire: Imprimerie Ntionale, 1937.

12. Martyre de saint Macaire // Les actes des martyrs de l’Égypte / éd., transl. H. Hyvernat. Paris: Ernest Leroux, 1886.

13. Martyrologe de saint Jean et de Siméon // Les actes des martyrs de l'Égypte / éd., transl. H. Hyvernat. Paris: Ernest Leroux, 1886.

14. Martyrologe de saint Piroou et de Athom // Les actes des martyrs de l’Égypte / éd., transl. H. Hyvernat. Paris: Ernest Leroux, 1886.

15. Nouveau martyr copte saint Nabraha / ed., Fr. transl. H. Munier // Bulletin de l'institut français d'archéologie orientale. 1918. Vol. 15.

16. Papaconstantinou A. Hagiography in Coptic // Ashgate Research Companion to Byzantine Hagiography / ed. S. Efthymiadis. Aldershot - Burlington (VT), 2011. Vol. 1. Periods and Places.

17. Papaconstantinou A. @zía oikovouía. Les actes thébains de donation d'enfants ou la gestion monastique de la pénurie // Travaux et Mémoires. 2002. № 14.

18. Sinuthii archimandritae vita // Sinuthii archimandritae vita et opera omnia I / ed. J. Leipoldt. Paris: e Typographeo reipublicae, 1906.

19. The Life of Bishop Pisentius, by John the Elder // Coptic Apocrypha in the Dialect of Upper Egypt. L.: Printed by order of the Trustees, 1913.

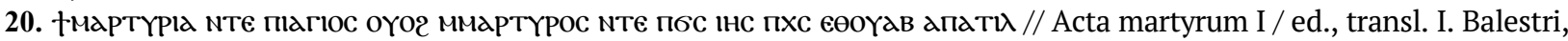
H. Hyvernat. Paris: e Typographeo reipublicae, 1907.

21. Vite dei monaci Phif e Longino / introduz., traduz. T. Orlandi, A. Campagnano. Milano: Cizalpino-Goliardica, 1975.

22. Zacharie. Vie de Jean Kolobos // Histoire des monastères de la Basse Egypte / ed. E. Amélineau. Paris: Ernest Leroux, 1894.

\section{Информация об авторах | Author information}

RU Франгулян Лилия Рубеновна ${ }^{1}$, к. филол. н.

${ }^{1}$ Институт востоковедения РАН, г. Москва;

Московский государственный лингвистический университет

EN Frangulian Lilia Rubenovna ${ }^{1}, \mathrm{PhD}$

${ }^{1}$ Institute of Oriental Studies of the Russian Academy of Sciences, Moscow; Moscow State Linguistic University

18liya8@gmail.com

\section{Информация о статье | About this article}

Дата поступления рукописи (received): 05.09.2021; опубликовано (published): 29.10.2021.

Ключевые слова (keywords): коптская агиография; образ облака; Библия; перемещение на облаке; исцеление тела; Coptic hagiography; image of cloud; Bible; moving on cloud; healing the body. 